\title{
Ventilation Distribution Heterogeneity at Rest as a Marker of Exercise Impairment in Mild-to-Advanced COPD
}

\author{
J. Alberto Neder, ${ }^{1,2}$ Conor D.J. 0'Donnell, ${ }^{1}$ Julia Cory, ${ }^{1}$ Daniel Langer, ${ }^{1}$ Casey E. Ciavaglia, ${ }^{1}$ Y. Ling, ${ }^{1}$ Katherine A. \\ Webb, ${ }^{1}$ and Denis E. O'Donnell ${ }^{1,2}$
}

1 Respiratory Investigation Unit, Queen's University \& Kingston General Hospital, Kingston, Ontario, Canada

2 Division of Respiratory and Critical Care Medicine, Queen's University \& Kingston General Hospital, Kingston, Ontario, Canada
Keywords: breathlessness, exertion, lung mechanics, pulmonary function tests

Correspondence to: Denis O'Donnell, 102 Stuart Street, Kingston, ON, Canada K7L 2V6, phone: 1-613-548-2339, fax: 1-613-548-1307, email: odonnel@queensu.ca

\begin{abstract}
The difference between total lung capacity (TLC) by body plethysmography and alveolar volume (VA) from the single-breath lung diffusing capacity measurement provides an index of ventilation distribution inequalities in COPD. The relevance of these abnormalities to dyspnea and exercise intolerance across the continuum of disease severity remains unknown. Two-hundred and seventy-six COPD patients distributed across GOLD grades 1 to 4 and 67 healthy controls were evaluated. The "poorly communicating fraction" (PCF) of the TLC was estimated as the ratio (\%) of TLC to VA. Healthy subjects showed significantly lower PCF values compared to GOLD grades 1 to $4(10 \pm 3 \%$ vs. $17 \pm 8 \%$ vs. $27 \pm 10 \%$ vs. $37 \pm 10 \%$ vs. $56 \pm$ $11 \%$, respectively; $p<0.05)$. Pulmonary gas exchange impairment, mechanical ventilatory constraints and ventilation-corrected dyspnea scores worsened across PCF tertiles $(p<0.05)$. Of note, GOLD grades 1 and 2 patients with the highest PCF values had pronounced exercise ventilatory inefficiency and dyspnea as a limiting symptom. In fact, dyspnea was a significant contributor to exercise limitation only in those with "moderate" or "extensive" PCF $(p<0.05)$. A receiver operating characteristics curve analysis revealed that PCF was a better predictor of severely reduced maximal exercise capacity than traditional pulmonary function indexes including $\mathrm{FEV}_{1}$ (area under the curve (95\% confidence interval) $=0.85(0.81-0.89)$, best cutoff $=33.4 \% ; p<0.01$ ). In conclusion, PCF is a readily available functional marker of gas exchange and mechanical abnormalities relevant to dyspnea and exercise intolerance across the COPD grades.
\end{abstract}

\section{Introduction}

Traditional spirometric measurements, such as forced expiratory flow rates, are poorly predictive of important clinical outcomes such as dyspnea and exercise intolerance in COPD (1). It is therefore desirable to develop novel physiological markers that better predict exercise intolerance, particularly in patients with milder airway obstruction $(2,3)$.

Adequate distribution of inhaled air is paramount to minimize the work of breathing and optimize the efficiency of the lung as a gas exchanger (4). In patients with COPD, there is well-established evidence that airflow distribution inequalities are sensitive markers of early physiological dysfunction $(5,6)$ and disease progression (7). These abnormalities are likely to further deteriorate under conditions of increased respiratory frequency and higher flow rates (8), e.g., during physical exercise. In this context, the presence of ventilation distribution abnormalities at rest might reasonably be associated 
with exaggerated ventilation-perfusion abnormalities during exercise. Thus, the associated increase in ventilatory requirements would be expected to have negative consequences for dyspnea and exercise tolerance (9). It is of clinical interest, therefore, to identify a marker of disturbed gas distribution at rest that would help to predict these relevant outcomes across the whole range of COPD severity.

It has long been recognized that inert gases dilution tests might provide valuable information about inspired gas distribution abnormalities and trapped gas volume (10). These tests are based on the logical assumption that the fraction of a highly insoluble gas (e.g., helium, methane) recovered at end expiration is inversely related to the number of lung units effectively participating in alveolar ventilation (11). Single breath techniques provide the simplest approach to estimate the poorly communicating fraction of total lung capacity (PCF, \% TLC). (Although the denomination "non-communicant" volume has been used in the past, scarcely ventilated unities better represent a "poor communicant" lung volume as air from non-ventilated areas that remain perfused is readily absorbed by the flowing venous blood.)

In practice, they are routinely used to assess the mixing gas volume for diffusing capacity of the lung for carbon monoxide $\left(\mathrm{DL}_{\mathrm{CO}}\right)$ i.e., "alveolar volume" (VA) (12). Using plethysmographically derived measurements of TLC as a frame of reference, PCF can be readily estimated, e.g., $1-(\mathrm{VA} / \mathrm{TLC})(\%)(13-15)$.

The current study, therefore, is the first to systematically investigate whether PCF-as an indirect measure of unequal ventilation distribution at rest and trapped gas volume (16-18) - would add to standard pulmonary function tests in predicting ventilatory constraints, arterial oxygen desaturation, and poorer exercise capacity across the continuum of airway obstruction in COPD. We hypothesized that regardless of disease severity PCF would relate to impaired dynamic mechanics and pulmonary gas exchange, and thus to the intensity of dyspnea and exercise intolerance. Confirmation of the study hypotheses would lend novel support for the use of PCF as a physiological marker of clinical outcomes in both clinical and research settings.

\section{Methods}

\section{Subjects and design}

This study involved a retrospective analysis of data collected between 2000 and 2012 at the Respiratory Investigation Unit, Queen's University and Kingston General Hospital, Kingston, ON, Canada. All patients had an established diagnosis of COPD according to current criteria (19), and they had been followed by the same respirologist (DOD) in a COPD-dedicated clinic for at least 6 months. Patients and controls had taken part in ethically approved research studies in which pulmonary function tests and an incremental cycle cardiopulmonary exercise test were performed as part of the study entry assessment.
Inclusion criteria for both groups included men and women 40 to 80 years of age, availability of both TLC by body plethysmography and VA from $\mathrm{DL}_{\mathrm{CO}}$ measurements, and lack of orthopedic, neuromuscular, cardiac, and metabolic conditions precluding the patient to safely undertake an incremental exercise test. Inclusion criteria for the COPD group in the afore-mentioned studies were consistent regarding: a) presence of shortness of breath on exertion and/or daily life, b) absence of asthma or any lung disease other than COPD, and c) absence of previous exacerbation in the preceding 6 weeks. The Queen's University and Affiliated Teaching Hospitals Research Ethics Board approved the use of these anonymous data sets and waived the need for patient informed consent (DMED-1659-13).

\section{Procedures}

\section{Lung function tests}

Spirometry, body plethysmography, and $\mathrm{DL}_{\mathrm{CO}}$ were performed by experienced researchers/technicians using automated testing equipment (2130 spirometer with 6200 Autobox DL or V6200 Autobox; SensorMedics; Yorba Linda, California) (20,21). All short-acting and long-acting bronchodilators were withdrawn for at least 4 hours and 12 hours, respectively. As patients had taken part in studies with different bronchodilators, GOLD grades were defined according to pre-bronchodilator $\mathrm{FEV}_{1}$. VA was derived from the single breath $\mathrm{DL}_{\mathrm{CO}}$ maneuver: methane as a tracer $(0.3 \%)$, inspired volume $>90 \%$ of the largest vital capacity in less than 2.5 seconds (4 seconds in COPD), breath-hold time (10 \pm 2 seconds) (22), sample collection time $<3$ seconds, washout volume of $0.75 \mathrm{~L}(0.5 \mathrm{~L}$ when vital capacity $<2 \mathrm{~L}$ ), appropriate clearance of dead space, and sample gas of $0.75 \mathrm{~L}(0.5 \mathrm{~L}$ when vital capacity < $1 \mathrm{~L})(21)$.

\section{Exercise tests}

Symptom-limited incremental exercise testing (10-20 $\mathrm{W} / \mathrm{min}$ ) was conducted on an electronically braked cycle ergometer using the Vmax229d Cardiopulmonary Exercise Testing System (SensorMedics) (23). Minute ventilation $(\dot{\mathrm{VE}}, \mathrm{L} / \mathrm{min})$, oxygen uptake $\left(\dot{\mathrm{VO}}_{2}, \mathrm{~L} / \mathrm{min}\right)$, carbon dioxide output $\left(\dot{\mathrm{VCO}}_{2}, \mathrm{~L} / \mathrm{min}\right)$ and tidal volume (VT, L) were averaged over the last 30 seconds at peak exercise. Oxygen saturation was measured by pulse oximetry $\left(\mathrm{SpO}_{2}, \%\right)$. Breathlessness and leg effort were rated according to the 10-point Borg category-ratio scale (24).

End-inspiratory lung volume (EILV, L) was calculated as end-expiratory volume (from inspiratory capacity) + VT and related to TLC. Peak VंE was also expressed relative to maximal ventilatory capacity $(\mathrm{MVC}(\mathrm{L} / \mathrm{min})=$ $\mathrm{FEV}_{1} \times 35$ (23). Due to the expected differences in maximal exercise capacity among the COPD grades, end-exercise EILV/TLC $(\times 100)$ and dyspnea scores were corrected for the ventilatory demand (peak VE) and peak VE /MVC corrected for the maximal metabolic stress $\left(\mathrm{V}_{2}\right)$. Peak 
$\dot{\mathrm{VO}}_{2}<1 \mathrm{~L} / \mathrm{min}$ and/or $<60 \%$ predicted (25) were $a$ priori selected to indicate severe exercise limitation $(23,27-28)$.

\section{Statistical analysis}

Values are reported as means \pm SD unless otherwise specified. A $p$ value of $<.05$ was considered significant in all analyses. Comparisons across subgroups were performed using analysis of variance (ANOVA) with posthoc testing of significant variables carried out using $t$ tests with Bonferroni adjustment for multiple comparisons. $\chi^{2}$ analysis tested the association between categorical variables. According to variables distribution, Pearson's $\mathrm{R}$ or Spearman's $\rho$ tested the correlation between continuous variables. Part (semi-partial) correlation calculated the correlation between PCF and TLC or VA in a multivariable regression analysis (asymptotic regression). An ROC curve analysis was used to contrast the diagnosis performance of the pulmonary function tests in predicting a severely reduced maximal exercise capacity.

\section{Results}

\section{Subject characteristics}

Data from 316 COPD patients and 69 healthy controls were reviewed. TLC by body plethysmography and/ or VA from $\mathrm{DL}_{\mathrm{CO}}$ measurements were not available in 40 patients and 2 controls. Therefore, 276 COPD patients distributed across GOLD grades 1 to 4 and 67 healthy controls fulfilled the inclusion criteria. Patients and controls were well matched for age (68.3 \pm 6.4 yrs vs. $66.7 \pm 7.0 \mathrm{yrs})$, gender (153/276 (53.6 \%) vs. $36 / 67$ (53.6\%) males) and body mass index (27.2 \pm $4.7 \mathrm{~kg} / \mathrm{m}^{2}$ vs. $\left.26.1 \pm 3.2 \mathrm{~kg} / \mathrm{m}^{2}\right)(p>0.05)$.

\section{PCF distribution}

Controls showed significantly lower PCF values compared to COPD grades 1 to $4(10 \pm 3 \%$ vs. $17 \pm 8 v$ s. 27 \pm 10 vs. $37 \pm 10$ vs. $56 \pm 11 \%$, respectively; $p<0.05$ for all between-group comparisons. There was, however, a wide distribution of PCF within a given GOLD grade (Figure 1). Only 2 controls showed a PCF value above

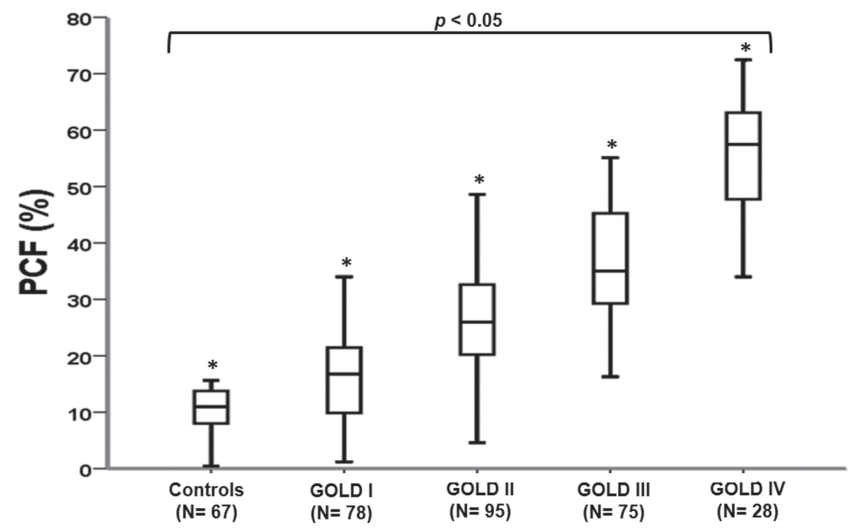

Figure 1. Boxplot (median, interquartiles and range) of PCF in healthy controls and COPD patients according to GOLD grades.
$17 \%$ with $91.4 \%$ of the values ranging from $5 \%$ to $15 \%$. Using tertiles as a frame of reference $(\mathrm{N}=92$ in each group), patients were separated into "mild" ( $\leq 23 \%)$, "moderate" (24-33\%) and "extensive" ( $\geq 34 \%)$ PCF.

\section{PCF Determinants}

PCF was more closely related to lower VA\% predicted than higher TLC\% predicted (Figure 2). In fact, non-linear regression analysis (asymptotic regression) revealed that the semi-partial correlation coefficients for PCF prediction were larger for VA\% than TLC\% ( -0.79 vs. $0.58 ; R^{2}=0.90 ; p<0.001$ ). Age, gender and body mass
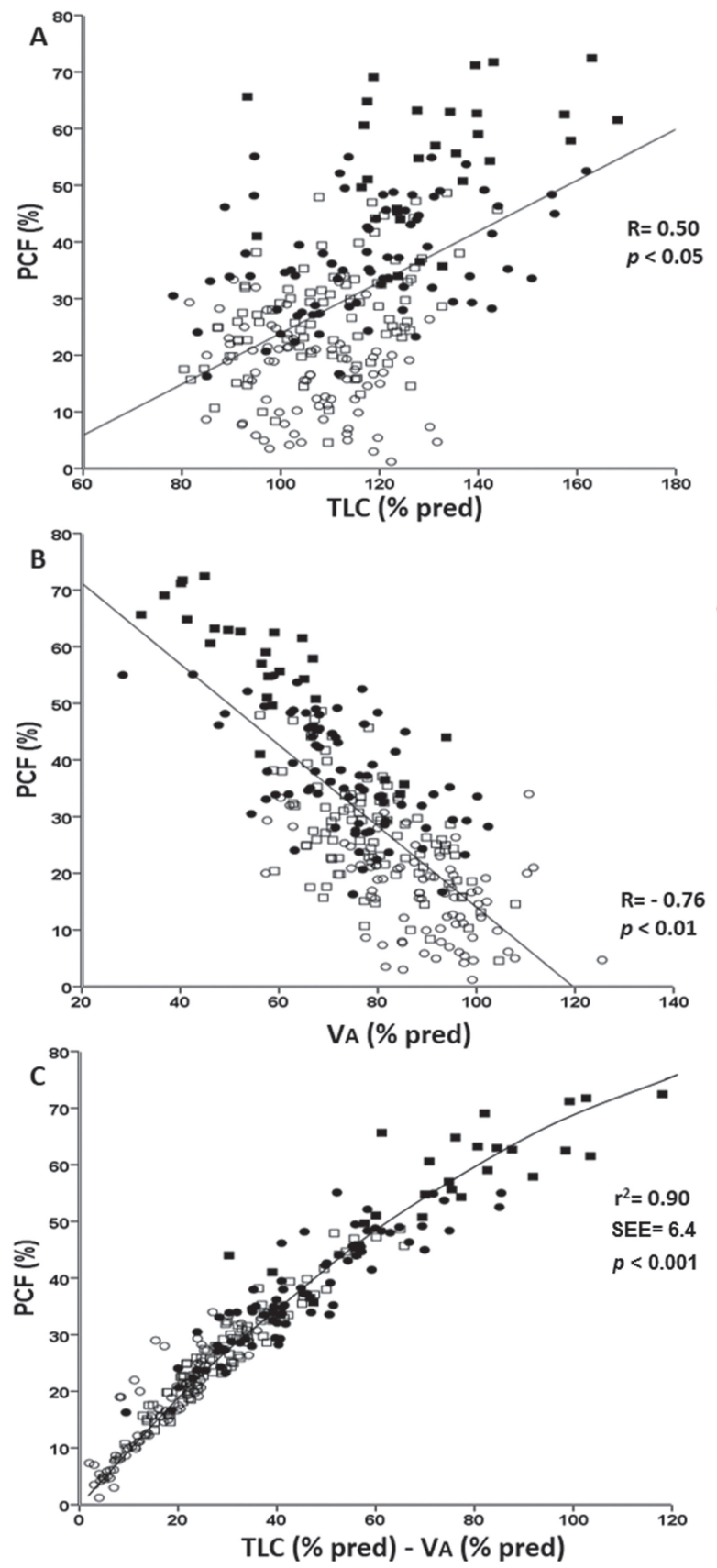

Figure 2. Significant correlations between \% predicted total lung capacity (TLC) (panel A) and alveolar volume (VA) (panel B) with PCF in COPD patients grades 1 to $4(\mathrm{~N}=276)$. Panel $\mathrm{C}$ shows the non-linear relationship (asymptotic regression) between \%TLC-\%VA differences and PCF. 
index showed no significant relationship with PCF $(p>0.05)$.

\section{PCF severity and functional impairment}

PCF correlated significantly with the main resting functional indexes across disease grades $(p<0.05)$; however, it varied substantially for a given $\mathrm{FEV}_{1}$, sRaw, $\mathrm{RV}$ and $\mathrm{DL}_{\mathrm{CO}}$ in individual patients (Figure 3). Markers of exercise impairment-including greater operational lung volumes and dyspnea-worsened across the PCF tertiles either in the whole sample (Table 1) or within GOLD grades 1 to 3 (Table 2) $(p<0.05)$. End-exercise dyspnea scores were at least equivalent to leg effort only in patients with "moderate" or "extensive" PCF (Figure 4). Forty patients (14.5\%) showed peak $\mathrm{SpO}_{2} \leq 90 \%$ : the fraction of patients with $\mathrm{SpO}_{2} \leq 90 \%$ increased across PCF tertiles (3/92 (3.2\%), 12/92 (13.0\%) and 25/92 (27.1\%) for "mild," "moderate" and "extensive" PCF, respectively $(p<0.05)$.

There were significant associations between "extensive" PCF and severe reductions in peak exercise capacity (specificity, positive likelihood ratio and posttest probability $=92.1 \%, 6.31$ and $90 \%$, respectively). In fact, a ROC curve analysis revealed that PCF was a better predictor of severe reductions in peak exercise capacity than $\mathrm{FEV}_{1}, \mathrm{RV}$, and $\mathrm{DL}_{\mathrm{CO}}$ (Figure 5).

Considering the potential for PCF to show early signs of airways disease in milder COPD (2, 9-12), we performed a more detailed analysis within GOLD grades 1 and 2. Compared to their counterparts with PCF $\leq 17 \%$, patients with higher PCF showed greater $\dot{\mathrm{VE}} / \dot{\mathrm{VCO}}_{2}$ and dyspnea/ $\dot{\mathrm{VE}}$ at peak exercise (GOLD 1: $31 \pm 3$ vs. $35 \pm 7$ and $0.07 \pm 0.03$ units/L/min vs. 0.11 \pm 0.04 units/L/min; GOLD 2: $33 \pm 2$ vs. $36 \pm 4$ and $0.06 \pm 0.04$ units $/ \mathrm{L} / \mathrm{min} v s .0 .13 \pm 0.05$ units $/ \mathrm{L} / \mathrm{min}$, respectively; $p<0.05)$. All GOLD 1 patients $(\mathrm{N}=14)$ and 33/36 (91.6\%) GOLD 2 patients with pronounced exercise ventilatory inefficiency $\left(\dot{\mathrm{VE}} / \dot{\mathrm{V} C \mathrm{CO}_{2}}>40\right)$ (23) showed $\mathrm{PCF}>17 \%$. In contrast, all patients from both groups with normal $\dot{\mathrm{VE}} / \mathrm{V}^{2} \mathrm{CO}_{2}(<34)(23)$ had $\mathrm{PCF} \leq$ $17 \%(p<0.01)$.
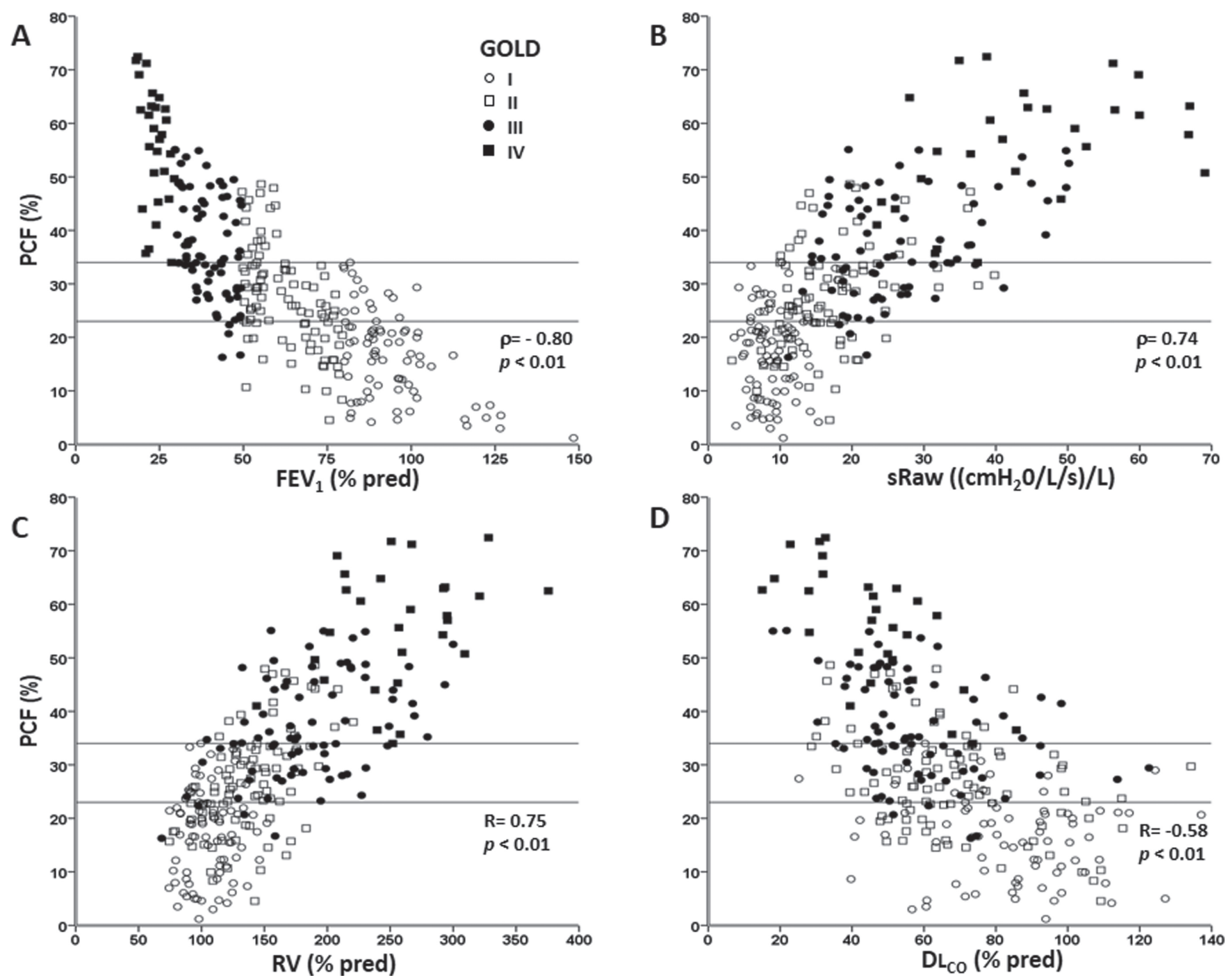

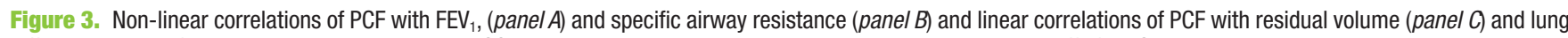
diffusing capacity for carbon monoxide (panel $D$ ) in COPD patients grades 1 to $4(\mathrm{~N}=276)$. Lines represent the cutoffs for PCF tertiles. 
Table 1. Selected resting and peak exercise variables in COPD patients separated by PCF tertiles

\begin{tabular}{|c|c|c|c|}
\hline & $\begin{array}{l}\text { "Mild" PCF } \\
(\mathrm{N}=92)\end{array}$ & $\begin{array}{c}\text { "Moderate" PCF } \\
(\mathrm{N}=92)\end{array}$ & $\begin{array}{l}\text { "Extensive" } \\
\text { PCF ( }=92)\end{array}$ \\
\hline \multicolumn{4}{|l|}{ Rest } \\
\hline $\mathrm{FEV}_{1}(\%$ pred $)$ & $83.4 \pm 18.9^{\star}$ & $59.7 \pm 19.6^{\dagger}$ & $39.2 \pm 16.9$ \\
\hline RV (\% pred) & $109.9 \pm 26.7^{\star}$ & $144.9 \pm 39.9^{\dagger}$ & $208.4 \pm 62.9$ \\
\hline IC (\% pred) & $103.1 \pm 20.7^{\star}$ & $85.5 \pm 19.3^{\dagger}$ & $66.8 \pm 19.6$ \\
\hline IC/TLC & $0.47 \pm 0.09^{\star}$ & $0.38 \pm 0.08^{\dagger}$ & $0.28 \pm 0.08$ \\
\hline sRaw $\left.\left(\mathrm{cmH}_{2} \mathrm{O} / \mathrm{L} / \mathrm{s}\right) / \mathrm{L}\right)$ & $10.7 \pm 4.5^{\star}$ & $18.4 \pm 8.7^{\dagger}$ & $30.8 \pm 14.7$ \\
\hline $\mathrm{DL}_{\mathrm{co}}(\%$ pred $)$ & $81.1 \pm 21.7^{*}$ & $66.5 \pm 20.6^{\dagger}$ & $52.1 \pm 18.8$ \\
\hline \multicolumn{4}{|l|}{ Peak exercise } \\
\hline \multicolumn{4}{|l|}{$\mathrm{V}_{2}$} \\
\hline$\%$ pred & $86.4 \pm 24.6^{\star}$ & $76.3 \pm 21.9^{\dagger}$ & $56.1 \pm 21.1$ \\
\hline$<1 \mathrm{~L} / \mathrm{min}$ & $5.0^{*}$ & $29.5^{\dagger}$ & 68.2 \\
\hline$<60 \%$ pred & $13.2^{*}$ & $26.4^{\dagger}$ & 60.4 \\
\hline $\mathrm{VE} / \mathrm{NCO}_{2}$ & $34 \pm 5^{\star}$ & $36 \pm 7^{\dagger}$ & $39 \pm 9$ \\
\hline (EILV/TLC)/汭 & $1.61 \pm 0.49^{\star}$ & $2.31 \pm 0.68^{\dagger}$ & $3.38 \pm 1.23$ \\
\hline (ن்/MVC)/ $\dot{\mathrm{VO}}_{2}$ & $0.50 \pm 0.18^{\star}$ & $0.74 \pm 0.29^{\dagger}$ & $1.17 \pm 0.52$ \\
\hline Dyspnea/V̈E & $0.09 \pm 0.04^{*}$ & $0.12 \pm 0.06^{\dagger}$ & $0.19 \pm 0.09$ \\
\hline
\end{tabular}

$p<0.05$ : *vs. "moderate" and "extensive"; 'vs. extensive. FEV 1 : forced expiratory volume in 1 second; FVC: forced vital capacity; RV: residual volume; IC: inspiratory capacity; sRaw: specific airway resistance; $\mathrm{DL}_{\mathrm{co}}$ : Iung diffusing capacity for carbon monoxide; $\mathrm{V}_{2}$ : oxygen uptake; $\dot{V}$ E: minute ventilation; $\dot{\mathrm{V}} \mathrm{CO}_{2}$ : carbon dioxide output; ElLV: end-inspiratory lung volume; TLC: total lung capacity; MVC: maximal ventilatory capacity.

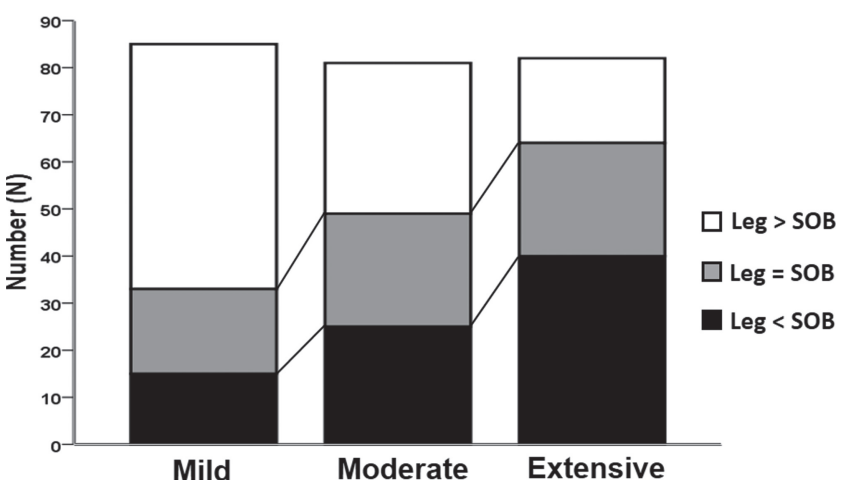

Figure 4. Absolute frequency of the main symptom (leg effort or shortness of breath (SOB) reported at the end of progressive exercise in COPD patients separated by PCF tertiles.

\section{Discussion}

This is the first study to evaluate the relevance of increased "poorly communicating" fraction of TLC (PCF) as a marker of exercise impairment in a large group of patients with COPD, GOLD grades 1 to 4 . Our main results support the study hypotheses as increased PCF was associated with higher operational lung volumes, arterial oxygen desaturation and exercise-related dyspnea scores at peak exercise across the continuum of airway obstruction. Of note, increased PCF was a better predictor of severe reductions in exercise tolerance than traditional functional indices including $\mathrm{FEV}_{1}$. These data provide novel evidence that PCF adds useful

Table 2. Selected resting and peak exercise variables in controls and COPD patients separated by PCF tertiles within GOLD grades

\begin{tabular}{|c|c|c|c|c|c|c|c|c|c|}
\hline & \multirow[b]{2}{*}{$\begin{array}{l}\text { Controls } \\
(\mathrm{N}=64)\end{array}$} & \multicolumn{2}{|c|}{$\begin{array}{l}\text { GOLD 1 } \\
(\mathrm{N}=78)\end{array}$} & \multicolumn{3}{|c|}{$\begin{array}{l}\text { GOLD } 2 \\
(\mathrm{~N}=95)\end{array}$} & \multicolumn{2}{|c|}{$\begin{array}{l}\text { GOLD 3 } \\
(\mathrm{N}=75)\end{array}$} & \multirow{2}{*}{$\begin{array}{c}\text { GOLD } 4 \\
(\mathrm{~N}=28) \\
\begin{array}{c}\text { Extensive" } \\
\text { PCF }\end{array}\end{array}$} \\
\hline & & $\begin{array}{l}\text { "Mild" } \\
\text { PCF } \\
(\mathrm{N}=59)\end{array}$ & $\begin{array}{c}\text { "Moderate" } \\
\text { PCF } \\
(\mathrm{N}=19)\end{array}$ & $\begin{array}{l}\text { "Mild" } \\
\text { PCF } \\
(\mathrm{N}=33)\end{array}$ & $\begin{array}{l}\text { "Moderate" } \\
\text { PCF } \\
(\mathrm{N}=40)\end{array}$ & $\begin{array}{c}\text { "Extensive" } \\
\text { PCF } \\
(\mathrm{N}=22)\end{array}$ & $\begin{array}{c}\text { "Moderate" } \\
\text { PCF } \\
(\mathrm{N}=33)\end{array}$ & $\begin{array}{c}\text { "Extensive" } \\
\text { PCF } \\
(\mathrm{N}=42)\end{array}$ & \\
\hline \multicolumn{10}{|l|}{ Rest } \\
\hline $\mathrm{FEV}_{1}(\%$ pred) & $115.9 \pm 14.1$ & $96.1 \pm 13.7^{\star \dagger}$ & $86.5 \pm 6.5^{*}$ & $70.1 \pm 8.8^{\star \star \ddagger}$ & $61.3 \pm 9.0^{*}$ & $55.0 \pm 3.5^{\star \dagger}$ & $42.5 \pm 5.0^{\star}$ & $37.7 \pm 6.3^{* \dagger}$ & $23.6 \pm 3.1^{*}$ \\
\hline IC (\% pred) & $108.2 \pm 16.4$ & $107.5 \pm 20.0^{\dagger}$ & $90.4 \pm 22.6^{*}$ & $94.7 \pm 16.1^{\text {*|\# }}$ & $87.6 \pm 19.2^{*}$ & $76.5 \pm 13.0^{\text {* }}$ & $78.8 \pm 14.7^{\star}$ & $71.1 \pm 18.1^{\text {㔹 }}$ & $51.8 \pm 11.6^{\star}$ \\
\hline IC/TLC & $0.47 \pm 0.07$ & $0.47 \pm 0.09^{\dagger}$ & $0.43 \pm 0.10^{*}$ & $0.43 \pm 0.08^{\star \star \downarrow \neq}$ & $0.38 \pm 0.08^{*}$ & $0.35 \pm 0.09^{\text {*t }}$ & $0.36 \pm 0.07^{\star}$ & $0.28 \pm 0.07^{\star \dagger}$ & $0.23 \pm 0.07^{\star}$ \\
\hline RV (\% pred) & $86.1 \pm 17.7$ & $101.2 \pm 23.3^{*}$ & $105.1 \pm 18.8^{*}$ & $120.7 \pm 28.9^{\star \mid \neq}$ & $137.4 \pm 26.0^{*}$ & $165.6 \pm 30.2^{\star+}$ & $167.0 \pm 44.8^{*}$ & $195.9 \pm 48.0^{\star+}$ & $261.6 \pm 61.3^{\star}$ \\
\hline sRaw (abs) & $5.29 \pm 1.77$ & $8.84 \pm 2.80^{*+}$ & $8.70 \pm 3.9^{*}$ & $13.4 \pm 5.0^{\star \star \ddagger}$ & $17.4 \pm 7.2^{*}$ & $19.5 \pm 8.5^{\star \dagger}$ & $17.7 \pm 4.7^{\star}$ & $24.7 \pm 6.7^{\star \dagger}$ & $43.5 \pm 13.5^{*}$ \\
\hline $\mathrm{D}_{\mathrm{L}} \mathrm{CO}$ (\% pred) & $101.9 \pm 21.8$ & $85.9 \pm 20.1^{\text {*t }}$ & $67.9 \pm 23.4^{\star}$ & $76.4 \pm 22.9^{\star \star \neq}$ & $68.7 \pm 20.1^{*}$ & $54.2 \pm 16.4^{\text {*t }}$ & $64.1 \pm 21.0^{*}$ & $53.2 \pm 16.6^{\text {* }}$ & $45.9 \pm 17.2^{*}$ \\
\hline \multicolumn{10}{|l|}{ Peak exercise } \\
\hline \multicolumn{10}{|l|}{$\dot{\mathrm{V}} \mathrm{O}_{2}$} \\
\hline$\%$ pred & $122.3 \pm 34.6$ & $94.1 \pm 16.0^{\text {*t }}$ & $90.9 \pm 25.1^{*}$ & $82.2 \pm 25.6^{\text {*|+ }}$ & $75.4 \pm 21.6^{*}$ & $66.7 \pm 12.5^{\text {*t }}$ & $67.5 \pm 17.2^{*}$ & $56.6 \pm 16.9^{\text {*ो }}$ & $39.5 \pm 10.0^{\star}$ \\
\hline$<1 \mathrm{~L} / \min (\%)$ & 0 & $6.8^{\star \dagger}$ & $55.4^{*}$ & $12.5^{\star \ddagger \ddagger}$ & $37.5^{*}$ & $66.7^{\star \dagger}$ & $37.5^{*}$ & $64.3^{\star \dagger}$ & $85.2^{*}$ \\
\hline$<60 \% \operatorname{pred}(\%)$ & 0 & $5.2^{* \dagger}$ & $43.8^{*}$ & $9.7^{\star \neq \neq}$ & $19.6^{*}$ & $66.7^{\star \dagger}$ & $41.4^{*}$ & $68.1^{*+}$ & $85.2^{*}$ \\
\hline$\dot{\mathrm{V}} / \mathrm{N} \mathrm{CO}_{2}$ & $33 \pm 5$ & $33 \pm 5^{\dagger}$ & $39 \pm 7^{*}$ & $35 \pm 4^{\star \downarrow \ddagger}$ & $37 \pm 5^{*}$ & $42 \pm 6^{\star+}$ & $35 \pm 7^{\star}$ & $38 \pm 11^{\text {*十 }}$ & $40 \pm 9^{*}$ \\
\hline$(\mathrm{EILV} / \mathrm{TLC}) / \mathrm{VE}$ & $1.17 \pm 0.35$ & $1.51 \pm 0.41^{\star+}$ & $2.10 \pm 0.64^{\star}$ & $1.79 \pm 0.57^{\star \neq \neq}$ & $2.23 \pm 0.64^{*}$ & $2.91 \pm 0.97^{\text {*t }}$ & $2.56 \pm 0.76^{*}$ & $3.21 \pm 0.98^{\star+}$ & $4.48 \pm 1.32^{\star}$ \\
\hline (VE/MVC)/WR & $0.28 \pm 0.11$ & $0.43 \pm 0.14^{\star \dagger}$ & $0.58 \pm 0.22^{\star}$ & $0.60 \pm 0.18^{\star \mid \neq}$ & $0.72 \pm 0.21^{*}$ & $0.97 \pm 0.32^{\text {*t }}$ & $0.75 \pm 0.18^{\star}$ & $1.01 \pm 0.36^{\star+}$ & $1.57 \pm 0.58^{\star}$ \\
\hline Dyspnea/VE & $0.05 \pm 0.03$ & $0.09 \pm 0.05^{*}$ & $0.09 \pm 0.04^{\star}$ & $0.08 \pm 0.04^{\star \neq \neq}$ & $0.12 \pm 0.05^{\star}$ & $0.18 \pm 0.05^{\star \dagger}$ & $0.14 \pm 0.07^{\star}$ & $0.19 \pm 0.10^{\star+}$ & $0.23 \pm 0.10^{\star}$ \\
\hline Dyspnea ${ }^{3}$ Leg (\%) & 0 & $5.1^{\star \dagger}$ & $26.4^{*}$ & $48.8^{\star \neq \ddagger}$ & $62.1^{*}$ & $73.9^{\star \dagger}$ & $49.5^{*}$ & $69.3^{\star \dagger}$ & $78.2^{*}$ \\
\hline
\end{tabular}

$p<0.05:{ }^{*}$ vs. controls, ${ }^{\dagger}$ vs. "moderate", ${ }^{\ddagger}$ vs. "moderate" and "extensive." $\mathrm{FEV}_{1}$ : forced expiratory volume in one second; FVC: forced vital capacity; RV: residual volume; IC: inspiratory capacity; sRaw: specific airway resistance; $\mathrm{DL}_{\mathrm{co}}$ : lung diffusing capacity for carbon monoxide; $\mathrm{V}_{2}$ : oxygen uptake; $\dot{\mathrm{VE}}$ : minute ventilation; $\dot{\mathrm{V}}_{\mathrm{C}} \mathrm{O}_{2}$ : carbon dioxide output; ElLV: end-inspiratory lung volume; TLC: total lung capacity; MVC: maximal ventilatory capacity; WR: work rate. 


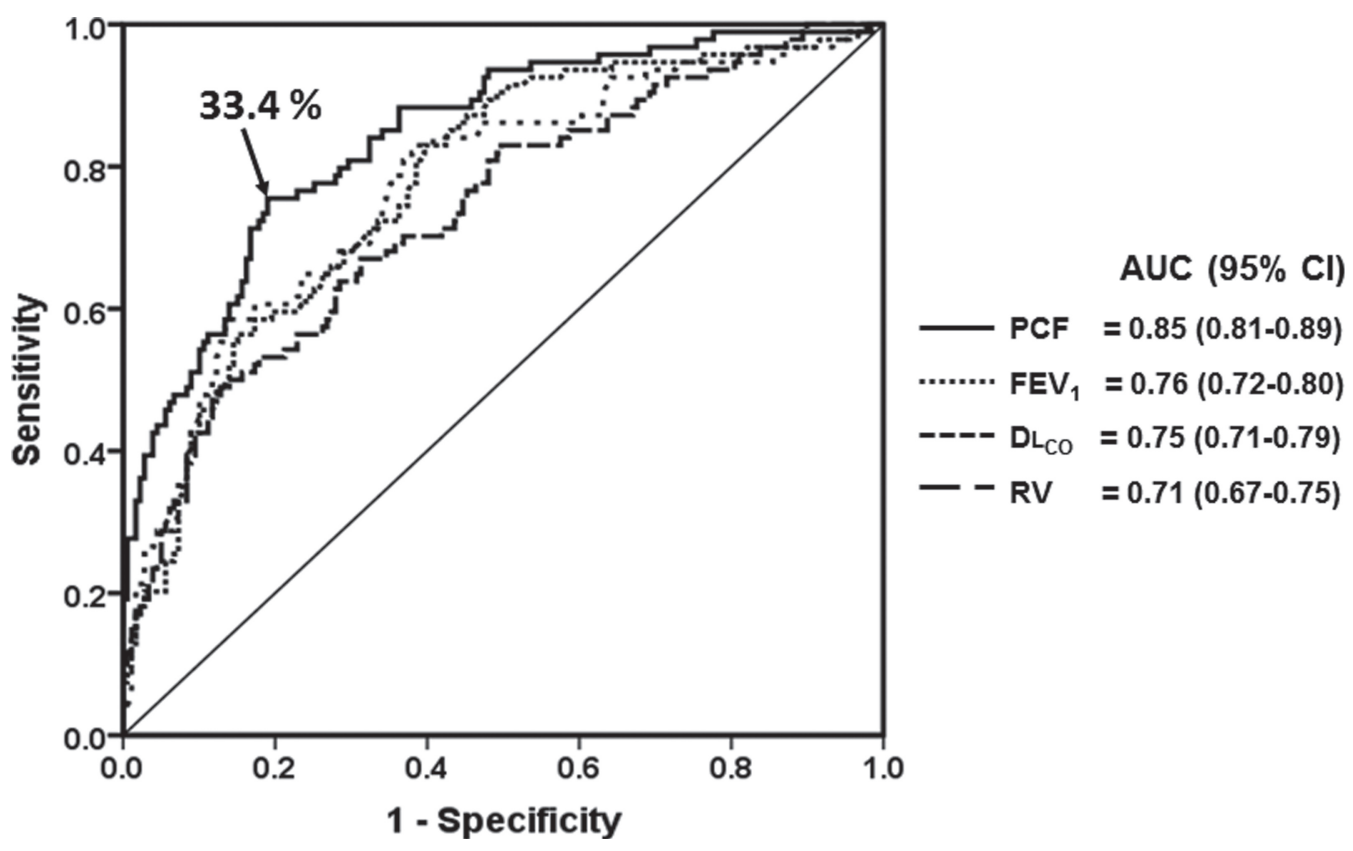

Figure 5. Receiver operating characteristics curve of selected physiological variables to predict a severely reduced peak exercise capacity in COPD patients GOLD grades 1 to $4(\mathrm{~N}=276)$. The best PCF cutoff is also highlighted. Definition of abbreviations: AUC: area under the curve; Cl: confidence interval; PCF: poorly communicant fraction; FEV: forced expiratory volume in 1 second; $\mathrm{DL}_{\mathrm{co}}$ : lung diffusing capacity for carbon monoxide; $\mathrm{RV}$ : residual volume.

information to standard PFTs to quantify the deleterious consequences of uneven resting ventilation on exercise capacity in mild-to-advanced COPD.

A solid body of knowledge shows that non-uniformity in the behavior of mechanical time constants (resistance $x$ compliance) results in asynchronous and inhomogeneous ventilation, which can be inferred by the extent to which VA underestimates TLC (9-18). Roberts and colleagues, for instance, demonstrated that PCF was the most sensitive and specific gas mixing index to indicate the presence of airflow obstruction in 100 COPD patients with reduced $\mathrm{FEV}_{1}$ (17). Punjabi et al. showed a strong association between the extent of $\mathrm{FEV}_{1} / \mathrm{FVC}$ decrease and PCF increase in a mixed population with airway obstruction (18). None of these studies, however, attempted to establish the added value of PCF to standard PFTs within GOLD stages or looked at its functional relevance to dyspnea and exercise intolerance.

In this context, a key finding of the present study was the relationship between increased PCF, higher dyspnea scores and poorer exercise tolerance (Figures 4 and 5). It is reasonable to assume that higher resting PCF points to non-uniform behavior of mechanical time constants of diverse alveolar units (9-18). Our results show that the presence of such derangements at rest had important implications for the development of abnormalities of dynamic mechanics (as suggested by higher ventilation corrected EILC/TLC) and ventilatory efficiency (increased $\dot{\mathrm{V}} / \dot{\mathrm{V}} \mathrm{CO}_{2}$ ) under the stress of exercise (Table 2).

Moreover, patients with higher PCF might have an exaggerated negative frequency-dependence of resistance and compliance $(4,8,32)$, which might result in more asynchronous emptying of lung units. Thus, the higher the resting PCF the earlier in exercise the respiratory system reached its physiological limits-either expressed as EILV/TLC or VE/MVC-with associated intolerable respiratory discomfort (Table 2). These results are increasingly supported by progressive failing in proper arterial oxygenation as PCF increased across the tertiles.

Another particularly interesting finding was the increase in PCF in approximately half of the patients with mild, grade 1 COPD (30). Of note, Ofir et al. (2) and Guenette et al. (33) demonstrated that exercise ventilatory inefficiency (increased $\mathrm{VE} / \mathrm{VCO}_{2}$ ) was a consistent finding in these patients despite the lack of increases in static lung volumes. In the current study, GOLD 1 patients with increased PCF had greater ventilatory inefficiency and dyspnea/VंE scores. These results suggest a mechanistic relationship between excessive ventilatory response and resting ventilation distribution inequalities-although we cannot rule out a contributory role of a lower $\mathrm{PaCO}_{2}$ setpoint in patients with milder airflow obstruction.

It is therefore conceivable that exercise amplified the resting ventilation distribution inequalities in GOLD I patients with higher PCF thereby increasing the exercise ventilatory requirements. In addition, decreases in tidal volume due to higher operating lung volumes (29) are likely to further magnify the ventilatory response in those patients. Our study, therefore, provides novel evidence that PCF increases the sensitivity of $F E V_{1}$ to uncover physiological impairment linked to poorer exercise performance in milder COPD.

It is noteworthy that the physiological consequences of COPD-related ventilation distribution inequalities and increased airway resistance might increase PCF by 
overestimating TLC by body plethysmography $(34,35)$ and/or reducing VA in the $\mathrm{DL}_{\mathrm{CO}}$ maneuver (14-16). In the second scenario, units with longer time constants would receive a smaller fraction of the tracer during the breath-holding period (36). The slower emptying units would also contribute less to the sampled expiratory air (13-15).

Apical lung units, which contain lower concentrations of the tracer than basal units, may not be well represented in the collected air as they will empty last (37). Our results indicate that TLC underestimation was indeed the most relevant mechanism for the TLC-VA differences (Figure 2). In fact, VA might be particularly reduced by methane dilution (compared to helium) as its lower solubility leads to a steeper methane $v s$ exhaled volume relationship in patients with airways obstruction (21).

We found substantial variation of PCF for a given value of $\mathrm{FEV}_{1}$ (Figure 3A) despite significant associations between PCF and GOLD stages (Figure 1). This helps to explain the well-known variation in symptoms and exercise tolerance among patients with a similar $\mathrm{FEV}_{1}(1)$. Thus, the explanation for this disparity might be the fact that gas mixing is predominantly influenced by small airways function whereas $\mathrm{FEV}_{1}$ is dominated by the large airways (32). Consequently, $\mathrm{FEV}_{1}$ might remain normal or only slightly decreased in the presence of uneven gas mixing in subjects with predominantly small airway obstruction (31-33). Obviously, large and small airway obstruction may coincide, particularly in more severe patients (as reviewed in ref. [5]). This might help explain the closer association between $\mathrm{FEV}_{1}$ and PCF in grade 4 patients (Figure $3 \mathrm{~A}$ ). From a clinical perspective, these results suggest that PCF adds more value to $\mathrm{FEV}_{1}$ in less severe patients, i.e., GOLD grades 1 to 3 .

The present study has, naturally, some strengths and limitations. From a positive perspective, this is the largest single study to date to combine respiratory and exercise evaluations (including operating lung volumes and dyspnea) across all COPD stages. Moreover, the database for the present communication was developed in a reference laboratory using highly standardized procedures. From a pathophysiological point-of-view, however, lack of arterial blood gases measurements during exercise might have contributed to obscure the potential link between increased PCF and worse arterial oxygenation and whether PCF would provide an indirect estimate of dead space ventilation. Concomitant measurement of intra-breath $\mathrm{D}_{\mathrm{L}} \mathrm{CO}$ might also have been useful to estimate whether VA dynamically changed with exercise.

We were unable to address longitudinal intra-subject progressions in PCF and the effects of interventions (e.g., bronchodilators) upon ventilation distribution inequalities (38). It also remains to be elucidated whether PCF might be influenced by specific disease phenotypes, particularly the extent of emphysema (39). Future studies should also address the modulating effects of lung bullae (and their specific location, i.e., apex $v s$. lung bases) on
PCF. Finally, comparison of PCF with more sophisticated-and, presumably, more accurate-tests of ventilation distribution heterogeneity (e.g., forced oscillation technique (40), multiple-breath nitrogen washout (41)) are warranted to further clarify its physiological meaning in different disease stages.

In conclusion, our results support the hypothesis that increased resting PCF - which can be readily derived from routine body plethysmography (TLC) and singlebreath $\mathrm{DL}_{\mathrm{CO}}$ measurements (VA) - is associated with gas exchange and mechanical abnormalities during exercise relevant to dyspnea and exercise intolerance across the spectrum of COPD severity. The structural and pathological determinants of PCF and its potential value as a physiological marker of clinical phenotypes, disease progression and treatment benefits deserve further study in this patient population.

\section{Declaration of Interest Statement}

The authors have no conflict of interests to declare. The authors alone are responsible for the content and writing of the paper.

\section{References}

1. Brusasco V. Pulmonary function studies, still a priority in COPD. J COPD 2014; 11:121-122.

2. Ofir D, Laveneziana P, Webb KA, Lam YM, et al. Mechanisms of dyspnea during cycle exercise in symptomatic patients with GOLD stage I chronic obstructive pulmonary disease. Am J Respir Crit Care Med 2008; 177:622-629.

3. Chin RC, Guenette JA, Cheng S, et al. Does the respiratory system limit exercise in mild chronic obstructive pulmonary disease? Am J Respir Crit Care Med 2013; 187:1315-1323.

4. Otis AB, McKerrow CM, Bartlett RA, et al. Mechanical factors in the distribution of pulmonary ventilation. J Appl Physiol 1956; 8:427-443.

5. Hogg JC, Macklem PT, Thurlbeck WM. Site and nature of airway obstruction in chronic obstructive lung disease. New Engl J Med 1968;278: 1355-1360.

6. Rodríguez-Roisin R, Drakulovic M, Rodríguez DA, Roca J, et al. Ventilation-perfusion imbalance and chronic obstructive pulmonary disease staging severity. J Appl Physiol (1985) 2009; 106:1902-1908.

7. Sandek K, Bratel T, Lagerstrand L, Rosell H. Relationship between lung function, ventilation-perfusion inequality and extent of emphysema as assessed by high-resolution computed tomography. Respir Med 2002; 96:934-943.

8. Engel LA. Dynamic distribution of gas flow. In: Macklem PT, Mead J. eds. Handbook of Physiology: The Respiratory System (Volume III). Bethesda, MD: American Physiological Society, 1986; 575-594, 598.

9. Ora J, Jensen D, O'Donnell DE. Exertional dyspnea in chronic obstructive pulmonary disease: mechanisms and treatment approaches. Curr Opin Pulm Med 2010; 16:144-149.

10. Teculescu DB, Stanescu DC. Total lung capacity in obstructive lung disease: comparative determination by single and multiple breath helium dilution. Bull Eur Physiopat)wl Respir, 1969; 5:453-464.

11. Ross JC, Ley GD, Krumholz RA, Rahbari H. A technique for evaluation of gas mixing in the lung. Studies in cigarette smokers and non-smokers. Am Rev Respir Dis 1967; 95:447453. 
12. Hughes JM, Pride NB. In defence of the carbon monoxide transfer coefficient Kco (TL/VA). Eur Respir J 2001; 17:168-174.

13. Schaanning CG, Gulsvik A. Accuracy and precision of helium dilution technique and body plethysmography in measuring lung volumes. Scand J Clin Lab Invest 1973; 32:271-277.

14. Pare PD, Wiggs BJR, Coppin CA. Errors in the measurement of total lung capacity in chronic obstructive lung disease. Thorax 1983; 38:468-471.

15. Rodenstein DO, Stanescu DC. Reassessment of lung volume measurement by helium dilution and body plethysmography in chronic airflow obstruction. Am Rev Respir Dis 1982; 126:1040-1044.

16. Burns CB, Scheinhorn DJ. Evaluation of single-breath helium dilution total lung capacity in obstructive lung disease. Am Rev Respir Dis 1984; 130:580-583.

17. Roberts CM, MacRae KD, Seed WA. Multibreath and single breath helium dilution lung volumes as a test of airway obstruction. Eur Respir J 1990; 13:515-520.

18. Punjabi NM, Shade D, Wise RA. Correction of single-breath helium lung volumes in patients with airflow obstruction. Chest 1998; 114:907-918.

19. Vestbo J, Hurd SS, Agustí AG, et al. Global strategy for the diagnosis, management, and prevention of chronic obstructive pulmonary disease: GOLD executive summary. Am J Respir Crit Care Med 2013; 187:347-365.

20. Miller MR, Crapo R, Hankinson J, et al. ATS/ERS Task Force. General considerations for lung function testing. Eur Respir J 2005; 26:153-161.

21. MacIntyre N, Crapo RO, Viegi G, et al. Standardisation of the single-breath determination of carbon monoxide uptake in the lung. Eur Respir J 2005; 13:720-735.

22. Jones RS, Meade F. A theoretical and experimental analysis of anomalies in the estimation of pulmonary diffusing capacity by the single breath method. Q J Exp Physiol Cogn Med Sci 1961; 46:131-143.

23. ERS Task Force Recommendations on the use of exercise testing in clinical practice. Eur Respir J 2007; 29:185-209.

24. Noble BJ, Borg GA, Jacobs I, Ceci R, Kaiser P. A category-ratio perceived exertion scale: relationship to blood and muscle lactates and heart rate. Med Sci Sports Exerc 1983; 15:523-528.

25. Jones NL, Makrides L, Hitchcock C, Chypchar T, et al. Normal standards for an incremental progressive cycle ergometer test. Am Rev Respir Dis 1985; 131:700-708.

26. Oga T, Nishimura $K$, Tsukino $M$, et al. Exercise capacity deterioration in patients with COPD: longitudinal evaluation over 5 years. Chest 2005; 128:62-69.

27. Cote CG, Pinto-Plata V, Kasprzyk K, et al. The 6-min walk distance, peak oxygen uptake, and mortality in COPD. Chest 2007; 132:1778-1785.
28. Albuquerque AL, Nery LE, Villaça DS, et al. Inspiratory fraction and exercise impairment in COPD patients GOLD stages II-III. Eur Respir J 2006; 28:939-944.

29. Laveneziana P, Webb KA, Ora J, et al. Evolution of dyspnea during exercise in chronic obstructive pulmonary disease: impact of critical volume constraints. Am J Respir Crit Care Med 2011; 184:1367-1373.

30. Peters MM, Webb KA, O’Donnell DE. Combined physiological effects of bronchodilators and hyperoxia on exertional dyspnoea in normoxic COPD. Thorax 2006; 61:559-567.

31. Kaczka DW, Lutchen KR, Hantos Z. Emergent behavior of regional heterogeneity in the lung and its effects on respiratory impedance. J Appl Physiol (1985) 2011; 110:1473-81.

32. Anthonisen NR. Tests of mechanical function. In: Macklem PT, Mead J. eds. Handbook of Physiology: The Respiratory System (Volume III). Bethesda, MD: American Physiological Society, 1986; 753-768.

33. Guenette JA, Webb KA, O`Donnell DE. Effect of fluticasone/ salmeterol combination on dyspnea and respiratory mechanics in mild-to-moderate COPD. Respir Med 2013; 107:708-16

34. O’Donnell CR, Bankier A, Stiebellehner L, et al. Comparison of plethysmographic and helium dilution lung volumes: which is best for COPD? Chest 2010; 137: 1108-1115.

35. Graham BL, Mink JT, Cotton DJ. Effect of breath-hold time on $\mathrm{DLCO}(\mathrm{SB})$ in patients with airway obstruction. J Appl Physiol 1985; 58:1319-1325.

36. Ruff F, Martin RR, Milic-Emili J. Previous volume history of the lung and regional distribution of residual volume. J Appl Physiol Respir Environ Exerc Physiol 1981; 51:313-316.

37. Horstman MJ, Mertens FW, Schotborg D, et al. Comparison of total-breath and single-breath diffusing capacity in healthy volunteers and COPD patients. Chest 2007; 131:237-244.

38. Kirby M, Mathew L, Heydarian M, et al. Chronic obstructive pulmonary disease: quantification of bronchodilator effects by using hyperpolarized ${ }^{3} \mathrm{He}$ MR imaging. Radiology 2011; 261:283-289.

39. van der Lee I, van Es HW, Noordmans HJ, et al. Alveolar volume determined by single-breath helium dilution correlates with the high-resolution computed by tomographyderived nonemphysematous lung volume. Respiration 2006; 73:468-773.

40. Timmins SC, Diba C, Farrow CE, et al. The relationship between airflow obstruction, emphysema extent, and small airways function in COPD. Chest 2012; 142:312-319.

41. Robinson PD, Latzin P, Verbanck S, et al. Consensus statement for inert gas washout measurement using multiple- and single-breath tests. Eur Respir J 2013; 41:507-522. 